\title{
Subzone Control of Air Distribution to Improve Thermal Comfort and Energy Efficiency
}

\author{
Sheng Zhang ${ }^{1 *}$, Yong Cheng ${ }^{2,3}$, Xiaoliang Shao ${ }^{4}$, Zhang Lin $^{5}$ \\ ${ }^{1}$ Department of Architecture and Civil Engineering, City University of Hong Kong, Hong Kong, China \\ ${ }^{2}$ Joint International Research Laboratory of Green Buildings and Built Environments, Ministry of Education, Chongqing University, \\ Chongqing, China \\ ${ }^{3}$ Key Laboratory of Three Gorges Reservoir Region's Eco-Environment, Ministry of Education, Chongqing University, Chongqing, \\ China \\ ${ }^{4}$ School of Civil and Resource Engineering, University of Science and Technology Beijing, Beijing, China \\ ${ }^{5}$ Division of Building Science and Technology, City University of Hong Kong, Hong Kong, China
}

\begin{abstract}
The conventional method for air distribution (e.g., mixing ventilation and stratum ventilation) controls the averaged thermal condition in the occupied zone to satisfy the averaged thermal preference of a group of occupants. However, since the thermal environment cannot be absolutely uniform, the microclimates of occupants can be distinct from the averaged thermal condition of the occupied zone. Moreover, the thermal preferences of occupants are well recognized to be diversified beyond the averaged value. Thus, the conventional method is unable to ensure thermal comfort and risks energy wastage because of overcooling. The method proposed by this study divides the occupied zone into several subzones, and determines the supply air parameters to optimize the overall performance regarding thermal comfort and energy efficiency of the subzones using the multi-criteria decision-making technique. Thermal comfort is indicated by the thermal deviation of the achieved thermal conditions of the subzones from the respective thermal preferences, and energy efficiency is indicated by the heat removal efficiencies of the subzones. Case studies based on experiments of stratum ventilation have demonstrated the effectiveness of the method proposed. Results show that the method proposed achieves thermal comfort for each subzone, and improves the overall performance by $2.1 \%$ to $31.0 \%$.
\end{abstract}

\section{Introduction}

Thermal comfort is the condition of mind that expresses the degree of satisfaction with a thermal environment [1]. Thermal comfort significantly affects the health and productivity of occupants. Thermal comfort can be evaluated by the deviation between the thermal condition and thermal preference. For example, ISO 7730 [2] employs Predicted Mean Vote (PMV) to indicate the thermal condition and assumes that PMV of zero is the thermal preference. The thermal deviation is firstly constrained to be less than a certain value for thermal comfort and secondly to be further reduced for thermal comfort improvement. ASHRAE 55 constrains the thermal deviation to be less than 0.5 for thermal comfort [1].

Air distribution, e.g., mixing ventilation, is widely used to provide indoor thermal comfort for a group of occupants [1]. The conventional control method determines the supply air parameters (e.g., the supply airflow rate and supply air temperature) to make the averaged thermal condition of the occupied zone to match the averaged thermal preference of all occupants in a room. It is based on the assumptions that the thermal environment is uniform and the occupants are typical people with identical thermal preferences. However, the thermal environment cannot be perfectly uniform. Even for mixing ventilation, field tests have reported that the assumption of uniform thermal environment could lead to thermal discomfort [3]. On the other hand, it is well recognized that the thermal preferences of occupants are diversified due to the differences in age, gender, thermal history, society culture, etc. [3]. The difference in thermal preferences among occupants has been reported to be frequently greater than one scale in the 7-point thermal sensation scale, indicating a difference in the thermally preferred air temperature up to $3^{\circ} \mathrm{C}$ [4]. As a result, the conventional method is unable to ensure that the microclimates of occupants satisfy the thermal comfort requirements. This explains the frequent complaints about thermal discomfort in practice [3]. Moreover, it has been reported to be highly possible for the conventional method to cause overcooling, which results in energy wastage of the air conditioning system [3].

\footnotetext{
* Corresponding author: shezhang-c@my.cityu.edu.hk
} 
Therefore, this study proposes a method to control the operation of air distribution to improve both thermal comfort and energy efficiency. The proposed method divides the occupied zone into subzones, and controls the supply air parameters to energy efficiently make the thermal conditions of the subzones to match the respective thermal preferences. Cases studies based on stratum ventilation have been conducted to demonstrate the effectiveness of the method proposed. Stratum ventilation is an energy-efficient air distribution [5]. It supplies conditioned air directly into the occupied zone to form the lowest air temperature and highest air velocity at the head level. Since the head is the most sensitive body part for thermal comfort, stratum ventilation could efficiently cool the body [3]. Stratum ventilation has been demonstrated to save the annual energy consumption of the air conditioning system for thermal comfort by at least $44 \%$ when compared with mixing ventilation in Hong Kong [6].

\section{Methodology}

\subsection{Subzone control method proposed}

Figure 1 shows that the method proposed includes three steps. In the first step, the supply air parameters and exit air temperature are monitored, which can be readily executed by the building management system [7]. In the second step, the monitored supply air parameters and exit air temperature are used to predict the thermal conditions of the subzones (e.g., Subzones A-D in Figure 2). It is noted that the subzones share the same supply air parameters and exit air parameters. The supply air parameters and the indoor and outdoor conditions determine the thermal environment, and the exit air temperature reflects the indoor and outdoor conditions. Thus, the thermal environment, including the thermal conditions of the subzones, can be modelled by the supply air parameters and exit air temperature (i.e., $f_{\mathrm{i}}$ in Figure 1), which has been experimentally validated by Zhang et al. [7, 8]. The exit air temperature refers to the temperature of the air leaving the room. The models $\left(f_{i}\right)$ require to be pre-determined in practice, which can be conducted during the commissioning stage. If the predicted thermal conditions of subzones fulfil the respective thermal comfort requirements, e.g., PMV within \pm 0.75 [8], the supply air parameters will be maintained. Otherwise, the supply air parameters need to be updated in the third step. All possible operation alternatives will be considered in the third step. Firstly, the thermal conditions of the subzones under each operation alternative are checked to sort out the potential operation alternatives fulfilling the thermal comfort requirements of all subzones (Equation 1). The ones failing the thermal comfort requirements are removed by assigning their overall performances to be worst (i.e., zero). Thus, the thermal comfort of each subzone can be ensured. It is noted that the cooling load is assumed to keep unchanged before and after the updating [9]. The exit air temperature can be calculated by Equation 2 for the thermal condition evaluation $\left(f_{\mathrm{i}}\right)$. Secondly, from the potential ones, the operation alternative with the best overall performance regarding thermal comfort and energy efficiency is selected to be the optimal operation. Thermal comfort is indicated by the thermal deviation between the thermal conditions of the subzones and the respective thermal preferences (Equation 3). A small thermal deviation denotes a more comfortable thermal environment. Energy efficiency is indicated by the heat removal efficiencies of the subzones (Equations 4 and 5) [10]. The heat removal efficiency is a widely used ventilation efficiency indicator, and a larger heat removal efficiency indicates a higher energy efficiency [10]. The heat removal efficiencies of the subzones can also be modelled by the supply air parameters and exit air temperature (i.e., $g_{i}$ in Figure 1), because the air temperatures of the subzones are functions of the supply air parameters and exit air temperature [7, 8]. The models of the heat removal efficiencies of the subzones are also required to be pre-determined in practice. The multi-criteria decision-making technique is used to make a trade-off between thermal comfort and energy efficiency. Based on the normalized thermal deviation and energy efficiency between zero and one (Equations 6 and 7), the multi-criteria decision-making technique calculates the overall performance with the user-defined weighting factors towards thermal comfort and energy efficiency (Equation 8) [11]. The overall performance is between zero and one, and a larger value indicates a better overall performance. It is noted that the above three steps need to be conducted periodically to maintain thermal comfort energy-efficiently for all subzones.

$$
\begin{gathered}
\alpha_{\mathrm{i}}<P M V_{\mathrm{i}}-\omega_{\mathrm{i}}<\beta_{\mathrm{i}} \\
Q_{\mathrm{cl}}=\rho c_{\mathrm{p}} V_{\mathrm{s}}\left(T_{\mathrm{e}}-T_{\mathrm{s}}\right) \\
T D=\sqrt{\frac{1}{m} \sum_{i=1}^{m}\left(P M V_{\mathrm{i}}-\omega_{\mathrm{i}}\right)^{2}} \\
H R E_{\mathrm{i}}=\frac{T_{\mathrm{e}}-T_{\mathrm{s}}}{T_{\mathrm{i}}-T_{\mathrm{s}}} \\
E E=\sqrt{\frac{1}{m} \sum_{i=1}^{m} H R E_{\mathrm{i}}^{2}} \\
\overline{T D_{\mathrm{j}}}=\frac{T D_{\max }-T D_{\mathrm{j}}}{T D_{\max }-T D_{\min }} \\
\overline{E E_{\mathrm{j}}}=\frac{E E_{\mathrm{j}}-E E_{\min }}{E E_{\max }-E E_{\min }} \\
P_{\mathrm{j}}=\gamma \bar{T} \overline{D_{\mathrm{j}}}+\delta \bar{E} \bar{E}_{\mathrm{j}}
\end{gathered}
$$

where $E E$ is the energy efficiency; HRE is the heat removal efficiency; the subscript $i$ indicates Subzone $i$; the subscript $j$ indicates Operation Alternative $J ; m$ is the number of subzones; $\max$ is the maximal value; $\min$ is the minimal value; $n$ is the number of operation alternatives; $P$ is the overall performance; $P M V$ is the Predicted Mean Vote; $Q_{\mathrm{cl}}$ is the cooling load $(\mathrm{kW}) ; T D$ is the thermal deviation; $T_{\mathrm{s}}$ and $T_{\mathrm{e}}$ are the supply and exit air temperatures respectively $\left({ }^{\circ} \mathrm{C}\right) ; \quad T_{\mathrm{i}}$ is the air temperature of Subzone $i\left({ }^{\circ} \mathrm{C}\right) ; V_{\mathrm{s}}$ is the supply airflow 
rate $\left(\mathrm{m}^{3} / \mathrm{s}\right) ; \omega$ is the thermal preference; $a(<0)$ and $\beta$ $(>0)$ are the allowed deviations from the thermal preference for thermal comfort; $\gamma$ and $\delta$ are the weighting factors allocated to thermal comfort and energy efficiency, which are both between zero and one and the sum of them equals one; $c_{\mathrm{p}}$ is the specific heat capacity of air $\left(\mathrm{kJ} /\left(\mathrm{kg}^{\circ}{ }^{\circ} \mathrm{C}\right)\right) ; \rho$ is the air density $\left(\mathrm{kg} / \mathrm{m}^{3}\right)$.

\section{Monitoring supply and exit air parameters} $V_{\mathrm{s}}^{\prime}, T_{\mathrm{s}}^{\prime}, T_{\mathrm{e}}^{\prime}$

2. Evaluating thermal conditions of subzones Subzone $i: P M V_{\mathrm{i}}^{\prime}=f_{\mathrm{i}}\left(V_{\mathrm{s}}^{\prime}, T_{\mathrm{s}}^{\prime}, T_{\mathrm{e}}^{\prime}\right)$

$P M V_{\mathrm{i}}^{\prime} \in\left(\omega_{\mathrm{i}}+\alpha_{\mathrm{i}}, \omega_{\mathrm{i}}+\beta_{\mathrm{i}}\right) ?$ $i=1,2, \ldots, m$

$$
\text { No }
$$

\begin{tabular}{|} 
3. Updating supply air parameters \\
Operation alternatives: $\left(V_{\mathrm{sj}}, T_{\mathrm{sj}}\right) \quad j=1,2, \ldots, n$ \\
Thermal condition of Subzone $i: P M V_{i j}=f_{i j}\left(V_{\mathrm{sj}}, T_{\mathrm{sj}}, T_{\mathrm{ej}}\right)$ \\
Heat removal efficiency of Subzone $i: H R E_{i \mathrm{j}}=g_{i \mathrm{j}}\left(V_{\mathrm{sj}}, T_{\mathrm{sj}}, T_{\mathrm{ej}}\right)$ \\
Thermal deviation: $T D_{\mathrm{j}}=\sqrt{\frac{1}{m} \sum_{i=1}^{m}\left(P M V_{i j}-\omega_{\mathrm{i}}\right)^{2}}$ \\
Energy efficiency: $E E_{\mathrm{j}}=\sqrt{\frac{1}{m} \sum_{i=1}^{m} H R E_{i \mathrm{j}}{ }^{2}}$ \\
Overall performance: $P_{\mathrm{j}}=\gamma \overline{T D_{\mathrm{j}}}+\delta \overline{E E_{\mathrm{j}}}$ \\
Constraint: $P M V_{i \mathrm{j}} \in\left(\omega_{\mathrm{i}}+\alpha_{\mathrm{i}}, \omega_{\mathrm{i}}+\beta_{\mathrm{i}}\right)$ \\
Objective: $\operatorname{Max}\left(P_{1}, P_{2}, \ldots, P_{\mathrm{j}}, \ldots, P_{\mathrm{n}}\right)$
\end{tabular}

Fig. 1. Subzone control method proposed.

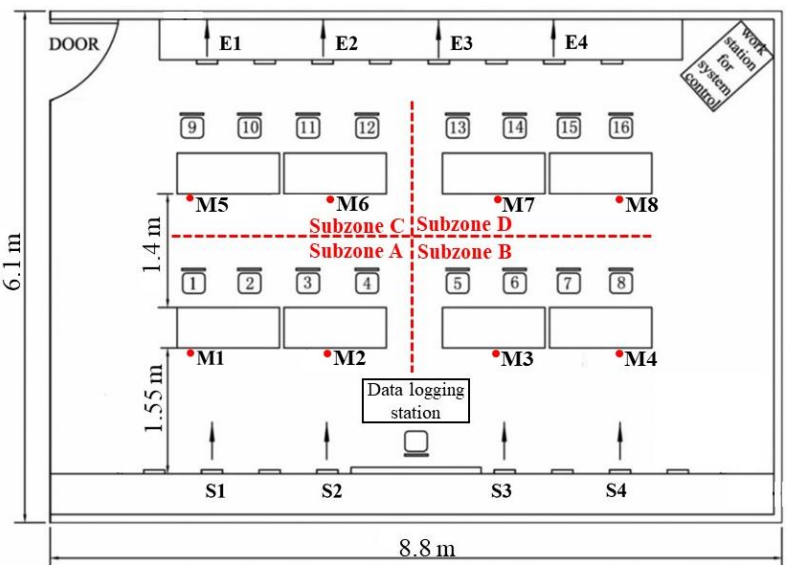

Fig. 2. Configuration of environment chamber.

\subsection{Experimentation}

The environment chamber of the stratum-ventilated typical classroom is located at City University of Hong Kong, with dimensions of $8.8 \mathrm{~m}$ (length) $\times 6.1 \mathrm{~m}$ (width) $\times 2.4 \mathrm{~m}$ (height) (Figure 2). The cool air is supplied horizontally from Diffusers S1-S4 on the side wall at the height of $1.3 \mathrm{~m}$ above the floor, and is exhausted from Exits E1-E4 on the side wall opposite to the supply diffusers at the same height. Sixteen thermal manikins in two rows simulate the occupants, with dimensions of around $400 \mathrm{~mm}$ (length) $\times 250 \mathrm{~mm}$ (width) $\times 1200 \mathrm{~mm}$ (height) and heated by a $100 \mathrm{~W}$ light bulb of each. The same as Zhang et al. [12], the occupied zone is evenly divided into four subzones according to the arrangement of the seats (Figure 2). The air temperature and velocity of each subzone are measured at two sampling points at the height of $1.1 \mathrm{~m}$ (e.g., M1 and M2 for Subzone A). Measurements at the height of $1.1 \mathrm{~m}$ are adequate for thermal comfort evaluation of stratum ventilation [13]. The averaged air temperature and velocity of the two measurements in one subzone represent the air temperature and velocity of that subzone. The supply air temperature is the averaged value of the measurements at Diffusers S1-S4, and the exit air temperature is the averaged value of the measurements at Exits E1-E4. The measurement accuracy of the SWEMA omnidirectional hot-wire anemometers is $\pm 0.2^{\circ} \mathrm{C}$ for the air temperature between $10^{\circ} \mathrm{C}$ and $40^{\circ} \mathrm{C}$, and $\pm 0.02 \mathrm{~m} / \mathrm{s}$ and $\pm 0.03 \mathrm{~m} / \mathrm{s}$ for the air velocity between $0.07 \mathrm{~m} / \mathrm{s}$ and $0.5 \mathrm{~m} / \mathrm{s}$ and between $0.5 \mathrm{~m} / \mathrm{s}$ and $3 \mathrm{~m} / \mathrm{s}$ respectively. The supply airflow rate is the sum of the measurements at Diffusers S1-S4 by the ALNOR balometer capture hood EBT731. The measurement accuracy is $\pm 3 \%$ of the reading between $0.012 \mathrm{~m}^{3} / \mathrm{s}$ and $1.181 \mathrm{~m}^{3} / \mathrm{s}$.

Table 1. Experimental conditions: Supply airflow rate $\left(V_{\mathrm{s}}\right)$ supply air temperature $\left(T_{\mathrm{s}}\right)$ and exit air temperature $\left(T_{\mathrm{e}}\right)$.

\begin{tabular}{|c|c|c|c|c|}
\hline \multicolumn{2}{|c|}{ Experiments } & $\begin{array}{c}V_{\mathrm{s}} \\
\left(\mathrm{m}^{3} / \mathrm{s}\right)\end{array}$ & $\begin{array}{c}T_{\mathrm{s}} \\
\left({ }^{\circ} \mathrm{C}\right)\end{array}$ & $\begin{array}{c}T_{\mathrm{e}} \\
\left({ }^{\circ} \mathrm{C}\right)\end{array}$ \\
\hline \multirow{5}{*}{} & 1 & 0.272 & 19.81 & 23.79 \\
\cline { 2 - 5 } & 2 & 0.272 & 22.24 & 28.01 \\
\cline { 2 - 5 } & 3 & 0.201 & 23.03 & 30.20 \\
\cline { 2 - 5 } & 4 & 0.201 & 23.72 & 31.02 \\
\cline { 2 - 5 } & 5 & 0.272 & 24.99 & 30.45 \\
\cline { 2 - 5 } & 6 & 0.272 & 25.94 & 28.09 \\
\cline { 2 - 5 } & 7 & 0.373 & 26.41 & 27.58 \\
\cline { 2 - 5 } & 8 & 0.373 & 29.44 & 31.95 \\
\cline { 2 - 5 } & 9 & 0.373 & 21.87 & 25.07 \\
\cline { 2 - 5 } & 10 & 0.272 & 22.35 & 26.74 \\
\hline \multirow{5}{*}{ Series 1 } & 11 & 0.201 & 23.86 & 30.48 \\
\cline { 2 - 5 } & 12 & 0.373 & 26.32 & 30.48 \\
\cline { 2 - 5 } & 13 & 0.373 & 23.25 & 25.68 \\
\cline { 2 - 5 } & 14 & 0.373 & 25.30 & 29.71 \\
\cline { 2 - 5 } & 15 & 0.201 & 26.90 & 30.89 \\
\hline
\end{tabular}

Fifteen experiments are designed (Table 1), with the supply airflow rate between $0.201 \mathrm{~m}^{3} / \mathrm{s}$ and $0.373 \mathrm{~m}^{3} / \mathrm{s}$, supply air temperature from $19.81^{\circ} \mathrm{C}$ to $29.44^{\circ} \mathrm{C}$ and exit air temperature from $23.79^{\circ} \mathrm{C}$ to $31.95^{\circ} \mathrm{C}$. These cover the thermal environment of stratum ventilation generally encountered in practice [5]. The experiments are randomly divided into two series. Series 1 (Experiments 1 to 10) is used for developing the models of PMVs and air temperatures (for the calculation of the heat removal 
efficiencies) of the subzones. The model quality can be assessed by the coefficient of determination $\left(R^{2}\right)$. Series 2 (Experiments 11-15), which is not involved in the model development, is used to validate the models further. More details about the experiments can be found in Zhang et al. [7].

\section{Results}

\subsection{Models of thermal condition and energy efficiency}

When calculating the PMV of each subzone, the typical summer clothing level in Hong Kong of 0.57 clo and the near-sedentary activity level of 1.0 met are used [13]. The mean radiant temperature is assumed to be the same as the air temperature [1]. The relative humidity ranges from around $55 \%$ to $62 \%$ during the experiments, and the medium value of $58.5 \%$ is used [7]. With the measured air temperatures and velocities, the PMVs of subzones are calculated according to ASHRAE 55 [1]. The PMVs of the subzones in the experiments run from around -1.5 to 2.0 indicating a wide range of the thermal environment (Figure 3). Based on the results of Series 1, the PMVs of Subzones A-D are modelled as Equations 9-12 with $R^{2}$ of $0.998,0.945,0.993$ and 0.995 respectively. It is noted that because the supply airflow rate for the PMV models of Subzones A and B and the supply air temperature for the PMV model of Subzone C have $p$-values higher than 0.5 indicating statistical insignificance, they are removed from the respective PMV models. Figure 3 shows the predicted PMVs are reasonably close to the ones calculated from the measurements. The mean absolute errors of the PMVs predicted compared with those calculated from the measurements are $0.14,0.11,0.07$ and 0.05 scale for Subzones A-D respectively. Thus, the PMV models developed are accurate adequately for thermal comfort evaluation. It can be seen from Equation 4 that the accurate predictions of the air temperatures of the subzones are adequate for the accurate predictions of the heat removal efficiencies of the subzones, because the supply air temperature and exit air temperature are monitored (Figure 1). The air temperatures of the subzones in the experiments cover a wide range from around $23^{\circ} \mathrm{C}$ to $32^{\circ} \mathrm{C}$ (Figure 4). They are modelled as Equations 13 to 16 with $R^{2}$ of $0.998,0.994,0.999$ and 0.999 for Subzones A-D respectively. Similarly, the model terms with p-values higher than 0.5 are removed. Figure 4 shows that the predicted air temperatures of the subzones are reasonably close to the measurements, with the mean absolute errors of $0.11^{\circ} \mathrm{C}, 0.16^{\circ} \mathrm{C}, 0.08^{\circ} \mathrm{C}$ and $0.09^{\circ} \mathrm{C}$ for Subzones A-D respectively. Thus, the heat removal efficiencies of the subzones calculated based on the predicted air temperatures of the subzones can be reliably used for the energy efficiency evaluation.

$$
\begin{gathered}
P M V_{\mathrm{A}}=0.390 \overline{T_{\mathrm{s}}}+1.090 \overline{T_{\mathrm{e}}}-0.160 \\
P M V_{\mathrm{B}}=0.650 \overline{T_{\mathrm{s}}}+0.500 \bar{T}_{\mathrm{e}}-0.440 \\
P M V_{\mathrm{C}}=-0.240 \overline{V_{\mathrm{s}}}+1.430 \overline{\mathrm{e}_{\mathrm{e}}}+0.490 \\
P M V_{\mathrm{D}}=-0.190 \overline{V_{\mathrm{s}}}+0.340 \overline{T_{\mathrm{s}}}+0.980 \overline{T_{\mathrm{e}}}-0.079 \\
T_{\mathrm{A}}=1.07 \overline{T_{\mathrm{s}}}+3.07 \overline{\mathrm{T}_{\mathrm{e}}}+27.04 \\
T_{\mathrm{B}}=1.89 \overline{T_{\mathrm{s}}}+1.91 \overline{T_{\mathrm{e}}}+26.68 \\
T_{\mathrm{C}}=0.12 \overline{T_{\mathrm{s}}}+3.83 \bar{T}_{\mathrm{e}}+27.55 \\
T_{\mathrm{D}}=0.70 \overline{T_{\mathrm{s}}}+3.12 \overline{T_{\mathrm{e}}}+27.23 \\
\bar{x}=\frac{2\left(x-x_{\min }\right)}{x_{\max }-x_{\min }}-1
\end{gathered}
$$

where $\bar{T}_{\mathrm{e}}$ and $\bar{T}_{\mathrm{s}}$ are the normalized temperatures of exit and supply air respectively (Equation 17); $\bar{V}_{\mathrm{s}}$ is the normalized supply airflow rate (Equation 17); $\bar{x}$ is the normalized value, which is a widely used pre-processing method of the inputs of data-driven models 7 [7]; $x$ is the original value (Table 1 ); $x_{\max }$ and $x_{\min }$ are the maximal and minimal original values respectively.

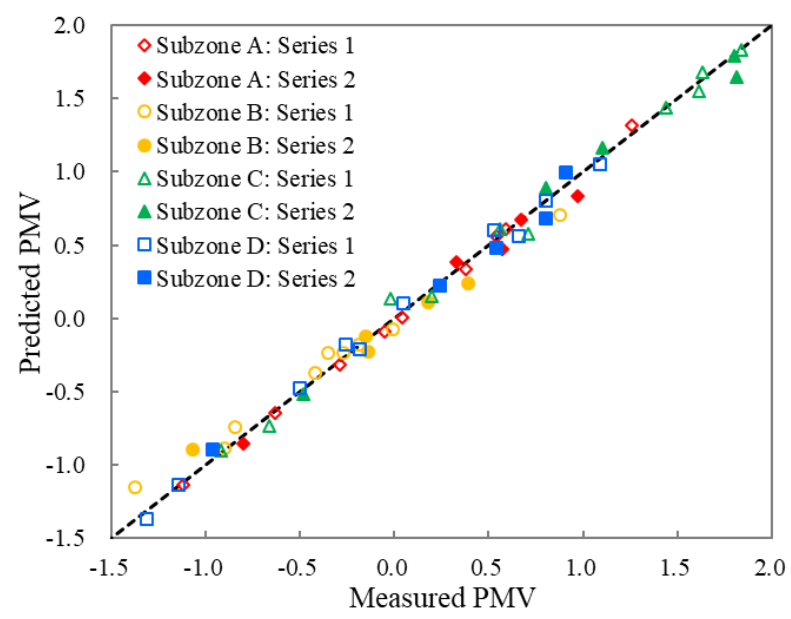

Fig. 3. Comparisons of PMVs from measurements and predictions of subzones.

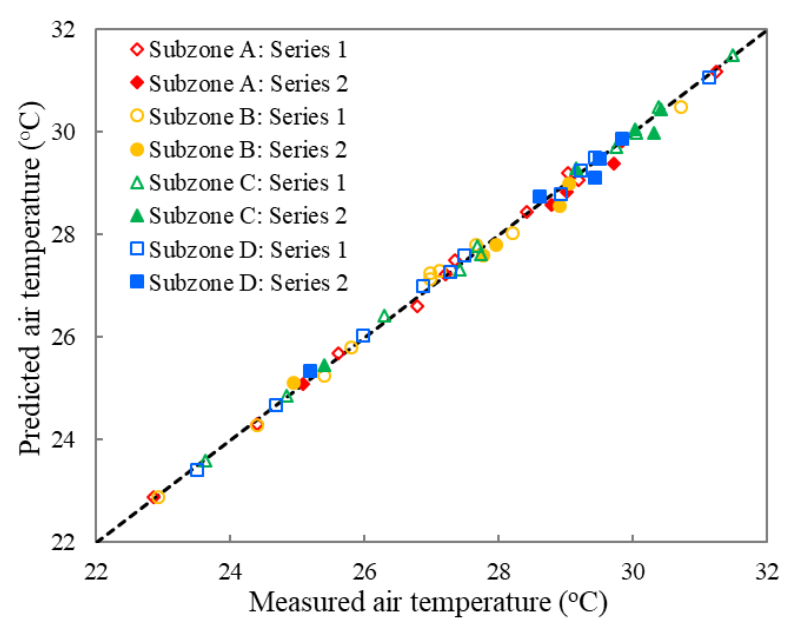

Fig. 4. Comparisons of measured and predicted air temperatures of subzones. 


\subsection{Effectiveness of method proposed}

The cooling load of the stratum-ventilated classroom is assumed to be $2.0 \mathrm{~kW}$ [9]. For thermal comfort, the PMVs of the subzones are constrained to be within \pm 0.75 [8]. There are 41 different supply airflow rates considered ranging from $0.201 \mathrm{~m}^{3} / \mathrm{s}$ to $0.373 \mathrm{~m}^{3} / \mathrm{s}$ with identical intervals (Section 2.2), and 61 different supply air temperatures from $20^{\circ} \mathrm{C}$ to $26^{\circ} \mathrm{C}$ with identical intervals [5]. When the supply air temperature is at $23^{\circ} \mathrm{C}$, Figure 5 shows that the PMVs of the four target zones decrease with the supply airflow rate. This is because the increase of the supply airflow rate elevates the air velocities in the subzones, thereby increasing the convective heat transfer between the occupants and indoor air to more efficiently cool the body. When the supply airflow rate is lower than $0.295 \mathrm{~m}^{3} / \mathrm{s}$, the PMV of Subzone $\mathrm{C}$ is higher than 0.75 indicating thermal discomfort. The differences in the PMVs of the subzones are explained by the air distribution characteristics of stratum ventilation [7]. To ensure thermal comfort of each subzone, the supply airflow rate lower than 0.295 $\mathrm{m}^{3} / \mathrm{s}$ would not be selected by the method proposed. However, of the four subzones, the averaged PMV which is concerned by the conventional method indicates thermal comfort except for the supply airflow rate lower than $0.205 \mathrm{~m}^{3} / \mathrm{s}$. In other words, the conventional method is unable to accurately identify the supply airflow rate which causes thermal discomfort in the subzones, e.g., the supply airflow rate between 0.205 $\mathrm{m}^{3} / \mathrm{s}$ and $0.295 \mathrm{~m}^{3} / \mathrm{s}$. Thus, the conventional method is unable to ensure thermal comfort for the subzones. Figure 6 shows that the variations of the heat removal efficiencies of the subzones with the supply airflow rate are complicated. Firstly, the sensitives of the heat removal efficiencies of different subzones to the supply airflow rate are different. For example, the heat removal efficiency of Subzone B is the most sensitive to the supply airflow rate. Secondly, the effects of increasing the supply airflow rate can impose negative effects on some subzones (e.g., Subzones A, B and D), but positive effects on the other subzones (e.g., Subzone C). These can be explained by the complicated airflow pattern and contribute to the complexity of the operation optimization.

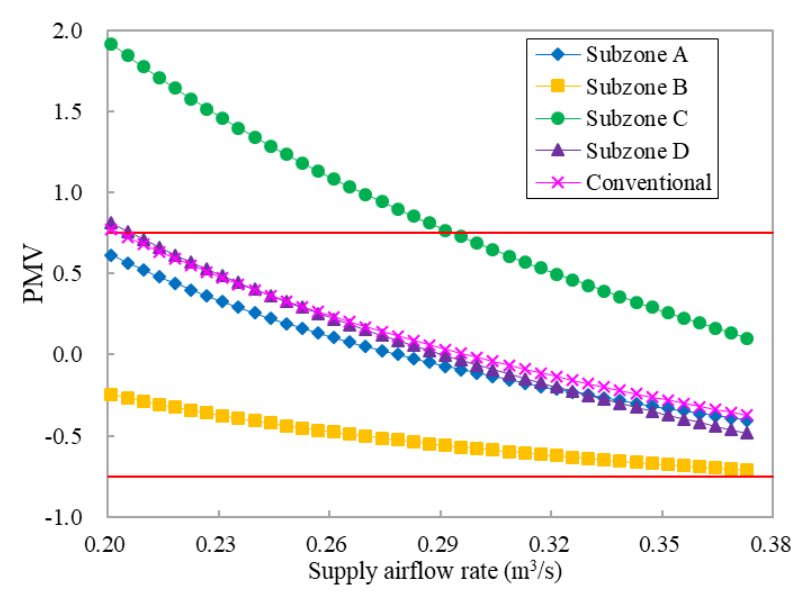

Note: The supply air temperature is constant at $23^{\circ} \mathrm{C}$.
Fig. 5. Variations of PMVs of subzones with supply airflow rates.

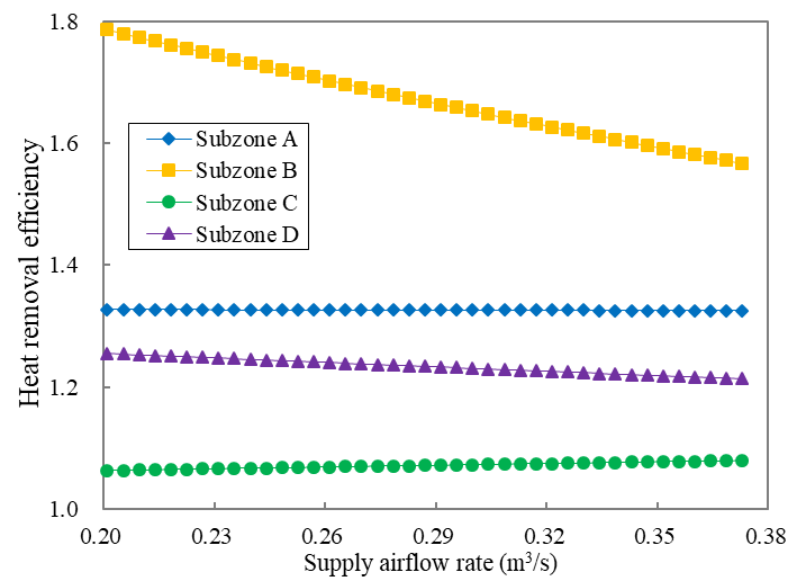

Note: The supply air temperature is constant at $23^{\circ} \mathrm{C}$.

Fig. 6. Variations of heat removal efficiencies of subzones with supply airflow rates.

Figure 7 shows that the variations of the thermal deviation and energy efficiency with the supply airflow rate. When the supply airflow rate is lower than 0.295 $\mathrm{m}^{3} / \mathrm{s}$, the overall performance is given a penalty to be the worst case (Section 2.1), which indicates that the thermal deviation and energy efficiency are also in their worst cases. Thus, the thermal deviation is 1.5 (Equation 3) and energy efficiency is nil (Equation 5). When the supply airflow rate increases from $0.296 \mathrm{~m}^{3} / \mathrm{s}$ to 0.373 $\mathrm{m}^{3} / \mathrm{s}$, energy efficiency decreases from 1.339 to 1.308 . To pursue the highest energy efficiency, the supply airflow rate of $0.296 \mathrm{~m}^{3} / \mathrm{s}$ is the optimal one. When the thermal preferences of the four subzones are all assumed to be zero, the thermal deviation decreases from 0.464 to the minimal value (i.e., 0.423 ) at the supply airflow rate of $0.330 \mathrm{~m}^{3} / \mathrm{s}$, and then increases to 0.478 . By targeting at the optimal thermal comfort, the supply airflow rate of $0.330 \mathrm{~m}^{3} / \mathrm{s}$ is the optimal one. Thus, the two criteria of thermal comfort and energy efficiency conflict mutually, and the multi-criteria decision-making technique is required to balance them reasonably (Section 2.1). When the weight factors of thermal comfort and energy efficiency are both 0.5 , which indicates thermal comfort and energy efficiency are equally preferred, the overall performance with the multi-criteria decision-making technique varies from 0.913 to 0.943 , and achieves its maximum at the supply airflow rate of $0.321 \mathrm{~m}^{3} / \mathrm{s}$ (Figure 8). 


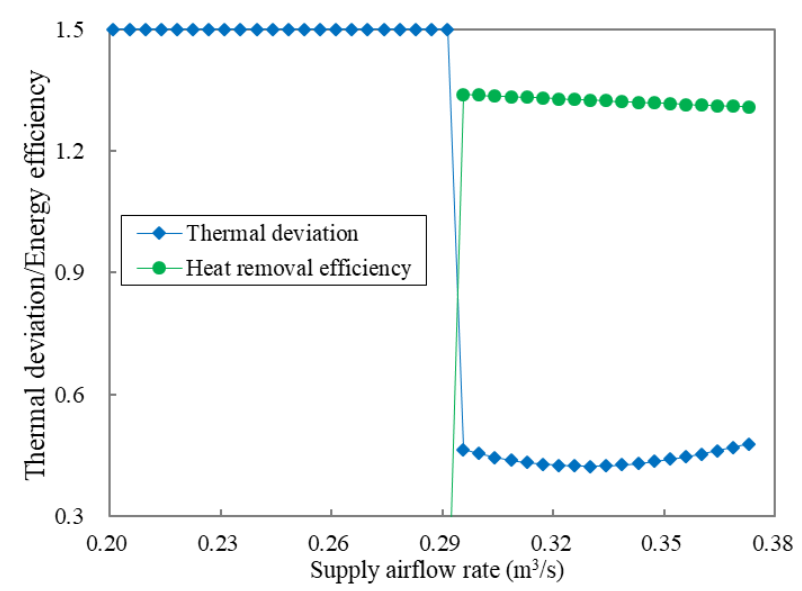

Note: The supply air temperature is constant at $23^{\circ} \mathrm{C}$.

Fig. 7. Variations of thermal deviation and energy efficiency with supply airflow rates.

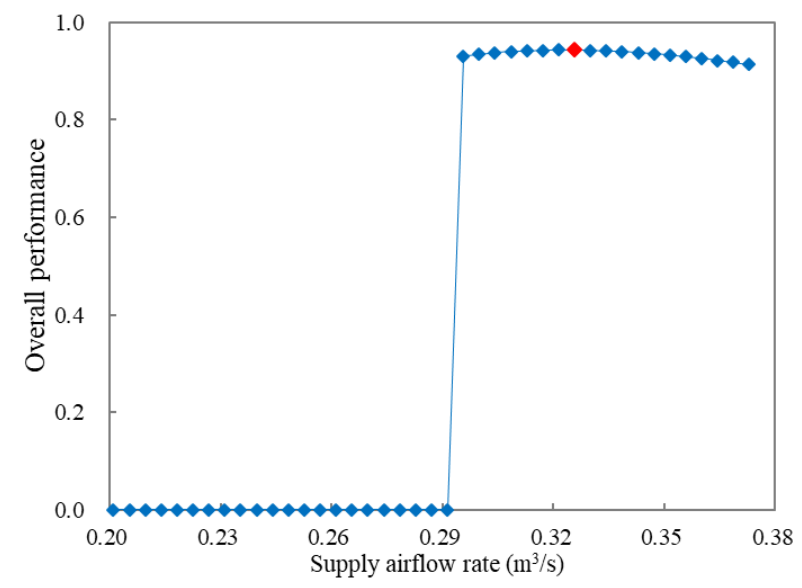

Note: The supply air temperature is constant at $23^{\circ} \mathrm{C}$.

Fig. 8. Variations of overall performance with supply airflow rates.

The above results demonstrate that the proposed method can firstly identify the potential operation alternatives to satisfy the thermal comfort requirements of the subzones; and secondly improves the overall performance by selecting the operation alternative with the maximal overall performance among the potential operation alternatives. The overall performance improvement can be quantified as the relative difference between the best and worst overall performances of the potential operation alternatives. When considering the 2501 operation alternative, i.e., the combinations of the 41 supply airflow rates and 61 supply air temperatures, Table 2 shows that for the 12 cases, the overall performance improvement achieved by the method proposed is $2.1 \%$ to $31.0 \%$. The 12 cases take into consideration different thermal preferences (identical thermal preferences with different preferred values and randomly produced differentiated thermal preferences among the subzones) [12] and different weighting factors of thermal comfort and energy efficiency. Therefore, the method proposed could effectively improve thermal comfort and energy efficiency. It is noted that this study uses PMV to indicate thermal comfort, but other thermal comfort indices can also be used by the proposed method, e.g., draft model, thermal comfort vote model and thermal acceptability model.

Table 2. Overall performance improvement by method proposed with different thermal preferences and weighting factors of thermal comfort and energy efficiency.

\begin{tabular}{|c|c|c|c|}
\hline & $\begin{array}{c}\gamma=0.5 ; \\
\delta=0.5\end{array}$ & $\begin{array}{c}\gamma=0.75 ; \\
\delta=0.25\end{array}$ & $\begin{array}{c}\gamma=0.25 ; \\
\delta=0.75\end{array}$ \\
\hline $\begin{array}{c}\omega_{A}=\omega_{B}= \\
\omega_{C}=\omega_{D}=0\end{array}$ & $11.3 \%$ & $26.5 \%$ & $3.5 \%$ \\
\hline $\begin{array}{c}\omega_{A}=\omega_{B}= \\
\omega_{C}=\omega_{D}=0.25\end{array}$ & $9.5 \%$ & $20.9 \%$ & $2.1 \%$ \\
\hline $\begin{array}{c}\omega_{A}=\omega_{B}= \\
\omega_{C}=\omega_{D}=-0.25\end{array}$ & $21.5 \%$ & $22.3 \%$ & $14.4 \%$ \\
\hline $\begin{array}{c}\omega_{A}=0.23 ; \\
\omega_{B}=-0.70 ; \\
\omega_{C}=0.52 ; \\
\omega_{D}=0.65\end{array}$ & $20.9 \%$ & $31.0 \%$ & $12.6 \%$ \\
\hline
\end{tabular}

Note: $\omega_{A}, \omega_{B}, \omega_{C}$ and $\omega_{D}$ are the thermal preferences of Subzones $A-D$ respectively; $\gamma$ and $\delta$ are the weighting factors of thermal comfort and energy efficiency respectively.

\section{Conclusions}

This study proposes a subzone control method to improve thermal comfort and energy efficiency of the operation of air distribution. The method proposed divides the occupied zone into subzones and controls the supply air parameters firstly to ensure thermal comfort of each subzone, and secondly to minimize the thermal deviation of the subzones from the respective thermal preferences and maximize the heat removal efficiencies of the subzones using the multi-criteria decision-making technique. Cases studies based on experiments of stratum ventilation have been conducted to demonstrate the effectiveness of the method proposed. Models of PMVs and air temperatures for the calculation of the heat removal efficiencies of the subzones have been developed and experimentally validated. With the models, results show that the method proposed can identify the potential operation alternatives fulfilling thermal comfort requirements of the subzones, but the conventional method risks thermal discomfort in the subzones. By considering different thermal preferences of the subzones and different weighting factors towards thermal comfort and energy efficiency, the method proposed improves the overall performance regarding thermal comfort and energy efficiency by $2.1 \%$ to $31.0 \%$. Therefore, this study contributes to the energy-efficient operation of air distribution for thermal comfort.

The work described in this paper is supported by a Basic Research Fund from Shenzhen Science and Technology Innovation Commission, China (Project No. 5033303).

\section{References}

1. ASHRAE 55, American Society of Heating, Refrigerating and Air-conditioning Engineers, Atlanta, Georgia (2017) 
2. EN ISO 7730, International Organization for Standardization, Geneva (1994).

3. J. Kim, F. Bauman, P. Raftery, E. Arens, H. Zhang, G. Fierro, M. Andersen, D. Culler, Build. Environment. 148, 348-360 (2018)

4. Z. Wang, R. de Dear, M. Luo, B. Lin, Y. He, A. Ghahramani, Y. Zhu, Build. Environ. 138, 181-193 (2018)

5. Y. Cheng, Z. Lin, A.M. Fong, Build. Environ. 92, 269-277 (2015)

6. Z. Lin, C.K. Lee, S. Fong, T.T. Chow, T. Yao, A.L.S. Chan, Energy Build. 43(1), 130-136 (2011)

7. S. Zhang, Y. Cheng, C. Huan, Z. Lin, Build. Environ. 144, 542-554 (2018)

8. S. Zhang, Y. Cheng, C. Huan, Z. Lin, Build. Environ. 149, 39-47 (2019)

9. S. Zhang, Y. Cheng, Z. Fang, Z. Lin, Build. Environ. 140, 107-118 (2018)

10. S. Zhang, Z. Lin, Z. Ai, F. Wang, Y. Cheng, C. Huan, Build. Environ. 148, 55-66 (2019)

11. S. Zhang, P. Huang, Y. Sun, Energy, 94, 654-665 (2016)

12. S. Zhang, Y. Cheng, M.O. Oladokun, Z. Lin, Build. Environ. 149, 39-47(2019)

13. S. Zhang, Y. Cheng, Z. Fang, C. Huan, Z. Lin, Appl Energy, 204, 420-431 (2017) 